\title{
Qualitative study on parental behavior as the source of dental fear development as reported by preschool students in Bandung
}

\author{
Arlette Suzy Setiawan ${ }^{1}$, Hendriati Agustiani ${ }^{2}$, Lenny Kendhawati ${ }^{2}$
}

Correspondence: Dr. Arlette Suzy Setiawan

Email: arlettesuzy@yahoo.com
'Department of Paediatric Dentistry, Faculty of Dentistry, Universitas Padjadjaran, Bandung, Indonesia, ${ }^{2}$ Faculty of Psychology, Universitas Padjadjaran, Bandung, Indonesia

\section{ABSTRACT}

Objective: This study aimed to analyze the contribution of parental behavior in DF development in preschoolchildren and seek its correlation with the level of DF. Materials and Methods: This study was addressed to preschoolchildren (3-6 years) in Bandung area using qualitative method through interviews with children. Data analysis was done using Spearman's rank correlation to find the correlation of parental behavior and level of DF. Results: Results revealed eight acquisition themes based on the parental behavior; two themes related to negative information, three themes related to direct conditioning, and three themes related to vicarious learning. Statistical analysis showed a significant Spearman rank correlation $r_{s} 0.42 \%$ or $17.38 \%(P<0.01)$. Conclusion: Parental behavior contributes to the development of DF in children at preschool ages through negative information, direct conditioning, and vicarious learning, as evidenced by the correlation of these parental behaviors with the level of DF in children.

Key words: Children, dental fear, parental behavior, qualitative study

\section{INTRODUCTION}

Dental fear (DF) is a significant problem for some individuals, especially for children and teenagers. The DF prevalence in children and teenagers is around $5 \%-20 \%$ in various countries and, in several cases, it leads to dental phobia (severe DF and anxiety). ${ }^{[1]}$ Recent systematic review stated that the prevalence is $10 \%-20 \%$, which depends on the survey scale used. ${ }^{[2]} \mathrm{DF}$ is related to low dental health-care use, treatment avoidance, and uncooperative behavior during dental consultation, ${ }^{[3]}$ which may result in dental treatment negligence and distress behavior, as well as triggering high temperament that will make dental care management challenging. ${ }^{[4]}$ Other than the child factor, it is considered that parents and dentist

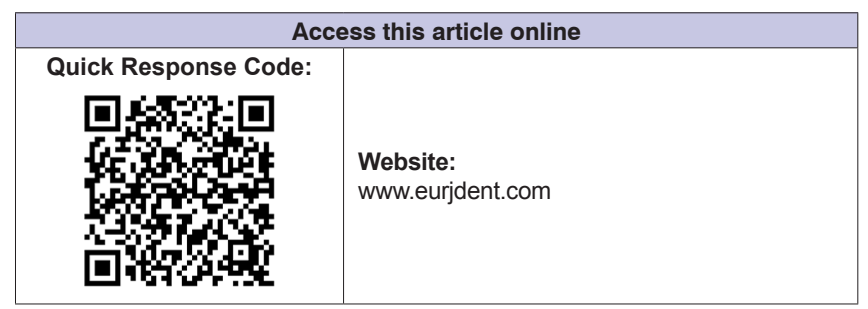

also play roles in difficult behavior during dental care. ${ }^{[5]}$ This contribution, which affects the child's cooperation during dental care, may include fear transmitted by the parents, unpleasant experience during previous dental treatments, lack of preparation for the first dental visit, or inadequate behavior in parenting practice. ${ }^{[6]}$

In general, psychology understands that fear is learned during early childhood. ${ }^{[7,8]}$ Rachman, in the late 1990s, developed a model that describes how an individual learns fear. The model consists of three main channels

This is an open access journal, and articles are distributed under the terms of the Creative Commons Attribution-NonCommercial-ShareAlike 4.0 License, which allows others to remix, tweak, and build upon the work non-commercially, as long as appropriate credit is given and the new creations are licensed under the identical terms.

For reprints contact: reprints@medknow.com

How to cite this article: Setiawan AS, Agustiani H, Kendhawati L. Qualitative study on parental behavior as the source of dental fear development as reported by preschool students in Bandung. Eur J Dent 2018;12:480-4.

DOI: 10.4103/ejd.ejd_258_18 
for learning fear, i.e., conditioning, information, and modeling learning. ${ }^{[9]}$

The influence of parental behavior is very strong on preschoolchildren. ${ }^{[10]}$ The parents, especially the mother, who experienced DF have a significant effect on children's fear behavior. ${ }^{[5]}$ Furthermore, factors related to parental norms, knowledge, and behavior are, in previous studies, expected to have contributions in developing children's negative behavior toward dental health; one of them is DF. ${ }^{[10]}$ The purpose of this study was to analyze the contribution of parental behavior in DF development in preschoolchildren.

\section{MATERIALS AND METHODS}

This study addressed preschoolchildren (3-6 years) in Bandung area. Five hundred and fifty children with DF level $\geq 30$ (based on Children Fear Survey Schedule-Dental Subscale score [CFSS-DS]) participated in the focus group interviews. The CFSS-DS was answered by parents in their child's place and has been validated for Indonesian population with Cronbach's coefficient of internal consistency, $\alpha=0.966 .{ }^{[11]}$ This study used qualitative method through interviews with children. ${ }^{[12]}$ Interview to the child included several questions about things that they acquired from parents which make them afraid to the dentist. The children answered based on their thoughts in their own words. The questions for the interview were developed based on children fear acquisition model by Rachman ${ }^{[9]}$ and included 13 items of focused questions. The questions include direct conditioning, vicarious learning, and negative information, composed in simple essay questions. Before being applied to the children, these questions were tested to other children in the same age group as controls. To ensure the validation of these questions, the triangulation method was used, consisting of a short survey, picture presentation, and optional questions to make sure that the children expressed their opinion appropriately and reflectively. ${ }^{[13]}$

To answer the research question about how parental behavior contributes to DF development in preschoolchildren, the qualitative data analysis was performed on data collected from interviews that were recorded, noted, and transcribed using the open inductive coding method. ${ }^{[12]}$ Two stages of data analysis approach were used to make sure that Rachman acquisition model guided the discussion so that questions that were initially not considered would appear in the discussion process to avoid data being "forced" into the work frame. ${ }^{[14]}$ In order to achieve it, the first theme analysis was performed using constant comparative method which was very useful for comparing data from several focus groups. After the analysis was completed, the researchers determined which part of the analyzed data included Rachman's fear acquisition model constructs. Furthermore, the relevant themes revealed were mapped into the construct. Spearman's rank correlation statistical analysis was used in this study to further seek the correlation between parental behaviors and the level of DF.

\section{RESULTS}

Eight Rachman's fear acquisition themes based on the parental behavior were observed/learned by the children [Table 1]. The first negative information response resulted in fear among children was obtained from the parents in the form of descriptions on a dentist as a person doing invasive dental treatments such as extraction and drilling. There were three variables obtained from the discussion: (1) if a child experiences tooth ache, he or she should go to a dentist; (2) if a child experiences tooth ache, the tooth

\begin{tabular}{|c|c|}
\hline \multicolumn{2}{|c|}{ Negative information } \\
\hline Theme 1 & $\begin{array}{l}\text { The children are afraid due to the negative } \\
\text { information that contains inappropriate information }\end{array}$ \\
\hline Theme 2 & $\begin{array}{l}\text { The children are afraid due to the negative } \\
\text { information that contains a threatening punishment }\end{array}$ \\
\hline \multicolumn{2}{|r|}{ Direct conditioning } \\
\hline Theme 1 & $\begin{array}{l}\text { The children are afraid because they are treated } \\
\text { inconveniently by their parents during the treatment }\end{array}$ \\
\hline Theme 2 & $\begin{array}{l}\text { The children are afraid because they hear } \\
\text { information that makes the dentist look bad/scary }\end{array}$ \\
\hline Theme 3 & $\begin{array}{l}\text { The children are afraid because they think that their } \\
\text { parents lie when taking them to visit dentist }\end{array}$ \\
\hline \multicolumn{2}{|r|}{ Vicarious learning } \\
\hline Theme 1 & $\begin{array}{l}\text { The children are afraid because they see their } \\
\text { parents' behavior during dental treatment }\end{array}$ \\
\hline Theme 2 & $\begin{array}{l}\text { The children are afraid because they see their } \\
\text { parents' behavior during dental treatment }\end{array}$ \\
\hline Theme 3 & $\begin{array}{l}\text { The children are afraid because of their parents' } \\
\text { description about what they felt during dental } \\
\text { treatment }\end{array}$ \\
\hline \multicolumn{2}{|r|}{ Introduction } \\
\hline Theme 1 & $\begin{array}{l}\text { Introduction that "causes DF in children" } \\
\text { means that the parents describe a dentist } \\
\text { as a person who does invasive dental } \\
\text { treatments such as extraction and drilling }\end{array}$ \\
\hline Theme 2 & $\begin{array}{l}\text { Introduction that "causes DF in children" means that } \\
\text { the parents never give any information about the } \\
\text { dentist so that the dentist becomes a stranger to the } \\
\text { children }\end{array}$ \\
\hline
\end{tabular}


must be extracted; and (3) if a child experiences tooth ache, the tooth must be drilled by a dentist.

The second negative response was the parental statement which was considered as a verbal threat, i.e., the dental visit was used as a threat to get the children to do their daily activities according to what the parents said, for example, brushing teeth. A statement of "If you don't brush your teeth, I will take you to the dentist" was the most reported response when answering "what did your parents tell you when you don't brush your teeth."

For the data triangulation, the children were asked to choose "yes" or "no" based on what they felt after listening to negative information about dentists from their parents, whether they were afraid when they were asked to visit the dentist or not. Eighty percent of the children $(n=440)$ answered "yes."

"The Direct Conditioning" from parental behavior was "parental dishonesty when taking children to visit a dentist." The second response was the parental behavior that made the dentist looked bad through the statement of "the dentist will be angry" if the children refused the treatment or cried in the dentist's office during a previous visit. The third response was the parental behavior that created discomfort among children during the previous visits. The discomfort might come from forcing or other small physical actions such as "pinching" that might result in trauma for the children.

For the triangulation, the children were asked to choose one of the three faces based on the modification of Facial Image Scale (smiling face $=$ not afraid, sad face $=$ afraid, and crying face $=$ very afraid). The number of "afraid" and "very afraid" responses was almost equal, i.e., $42 \%$ and $44 \%$, respectively. And, "not afraid" response was only $14 \%$.

"Vicarious learning theme" resulted that the parental behaviors during the treatment that potentially led to DF were divided into three types, i.e., parental behaviors that were heard, seen, and reported to the children. These behaviors include the facial expression and behaviors observed by the children during treatment. The second response was based on the report on the pain they felt during a recent dental treatment. Moreover, the last response was the behavior that was heard by the children. This behavior was the pain verbal expression, such as "ouch," or when parents refusing certain treatment, such as "don't extract it."
Data analysis using Spearman's rank statistical analysis [Table 2] revealed a correlation between parental behavior and the level of DF with statistically significant score $\mathrm{r}_{\mathrm{s}} 0.42$ or $17.38 \%(P<0.01)$. By sex, in boys, there was a relationship of $r_{s} 0.36$ or $12.75 \%(P<0.05)$, whereas in girls, the relationship was more significant with $r_{s} 0.47$ or $22.14 \%(P<0.01)$.

\section{DISCUSSION}

According to Piaget, the cognitive development of children assessed in this study is in the preoperational period, a stage where children are not able to control the mental operational (logically). This period is also identified by representational or symbiotic function developments where the child develops the ability to use things to represent other things using symbols such as language, picture, sign, and tools to symbolize something or an event. Through this ability, children are able to have imagination or fantasize anything.

Negative information on a condition can explain the development of fear or worsen the situation that creates fear toward an object/subject that is unrelated to the children. The negative information can strengthen the belief in dangers resulted from a certain stimulus. If the interaction with the stimulus happens, it can result in fear reactions. The information that causes fear will result in a behavior to avoid a stimulus or certain situation. And, this will reduce the chances to correct the wrong expectation that is already formed. ${ }^{[15]}$

In this study, the negative information is the parent's statement that relates dentists to invasive treatments such as extraction and drilling. Although the children never personally experience the treatment or observe other's experiences, the words "extraction" or "drilling" are understood by the children as an action that will cause pain. The negative expectation related to this invasive treatment may lead to actions to avoid dental treatments or a possibility to become a persistent condition, i.e., the child becomes afraid when he/she is told to visit a dentist. The second negative information response that can cause fear in children is the parent's statement that has tendency as a verbal threat, i.e., the parents make dental visits

Table 2: Correlation of parental behavior and dental
fear level in children
\begin{tabular}{lccccc}
\hline gender & $\boldsymbol{r}_{\mathrm{s}}$ & $\boldsymbol{t}$ & $\boldsymbol{P}$ & Meaning & $\left(\boldsymbol{r}_{\mathrm{s}}\right)^{2}$ \\
\hline All & 0.42 & 4.31 & $<0.01$ & Significant & 17.38 \\
Boys & 0.36 & 2.42 & $<0.05$ & Significant & 12.75 \\
Girls & 0.47 & 3.63 & $<0.01$ & Significant & 22.14 \\
\hline
\end{tabular}


a threat if the children do not do their daily routine properly, such as when they do not brush their teeth or when they eat too much sweet food.

How the negative information in the form of a threat can affect DF in children can be explained through associative learning, i.e., the main mechanism on how information causes fear. Associative learning is not a concept of a response-stimulus learning that is similar to reflect, but should be considered as a process when an individual develops an association in the memory (by learning) that a certain stimulus can predict an aversive result, i.e., condition of fear. ${ }^{[16]}$

The mechanism that underlies the threat information effect is similar to the process in direct conditioning. The threat information interacts with the direct learning experience to cause fear reaction. Children do not experience the daily activities as a tabula rasa, but they carry the information of certain stimulus or situation that can determine their fear level with them. ${ }^{[16]}$

In this study, it is uncertain whether the information of verbal threat is really experienced by the children as a direct conditioning, which is the core of children's fear acquisition. However, verbal information can be a path that affects this conditioning process. Children are afraid of dentists even though they do not know the dentist personally.

Based on the initial conditioning model of fear acquisition, a single exposure toward things related to a very aversive event can cause an individual to become afraid of those things. ${ }^{[9]}$ In this study, the direct conditioning is an event experienced by the children personally when they are in a dentist office or during treatment.

The children's response indicates parental behavior that is not honest when taking their children to a dentist. The parents told the children that they were going to a place which they would like, but the truth was they took the children to a dentist. The children feel that they are being deceived so that they express it by displaying negative behaviors. When the children show a negative behavior, the parents try to calm them by statements that make the dentist look bad, such as asking the children to calm down or else the dentist will be angry. If the children persist with the negative behavior, such as refusing the treatment, some parents still force them. This is a condition that makes the children feel uncomfortable.
The parental behavior that causes uncomfortable condition for the children in the dentist office is a conditioned stimulus combined with unconditioned aversive stimulus (dental treatment). Therefore, the children express a conditioned fear toward the dentist because they learn and expect that dental treatment is unpleasant because they are forced by their parents or because they receive negative statements about the dentist.

Another path of fear development in children is through vicarious learning. The fear can be learned by observing other individual's fear responses without any direct conditioning. ${ }^{[9]}$ The discussion result shows that the parental behavior during dental treatments has a potential to cause DF in children. The children learn fear through what they hear or see.

The study results show that children are afraid when observing the parents expressing fear during dental treatments. In line with a study performed by Askew and Field (2007), quoted by Du (2008), there is prospective experimental evidence that supports the vicarious learning roles in developing children's DF. In this study, animal pictures with fear, happy, and neutral expressions were shown to children aged 7-9 years. The threat perception was reported by the children on the animal picture with fear expression. ${ }^{[15]}$

The survey on preschoolchildren has a weakness because these children are in their developmental stage and tend to fantasize and to be different from others. ${ }^{[17]}$ To minimize the data inaccuracy, just like in other qualitative studies, data triangulation was performed. Furthermore, the interview technique was used where questions were asked repeatedly, which is considered to be able to minimize bias.

\section{CONCLUSION}

This qualitative study suggests that parental behavior contributes to the development of DF in children at preschool ages through negative information, direct conditioning, and vicarious learning. The negative information includes the parents' statement that links dentists to invasive treatments and information that can be interpreted as threatening. The direct conditioning is developed through parental behavior that creates discomfort for the children during the treatment. The last one, vicarious learning, is developed through parental behavior when they receive dental treatment. There is correlation between these parental behaviors and the level of DF in children. When 
analyzing parental behavior in line with child's DF level, it was found that the higher parental negative behavior, the higher DF level of the child.

\section{Financial support and sponsorship}

Nil.

\section{Conflicts of interest}

There are no conflicts of interest.

\section{REFERENCES}

1. Gao X, Hamzah SH, Yiu CK, McGrath C, King NM. Dental fear and anxiety in children and adolescents: Qualitative study using YouTube. J Med Internet Res 2013;15:e29.

2. Cianetti S, Lombardo G, Lupatelli E, Pagano S, Abraha I, Montedori A, et al. Dental fear/anxiety among children and adolescents. A systematic review. Eur J Paediatr Dent 2017;18:121-30.

3. Carrillo-Diaz M, Crego A, Armfield JM, Romero-Maroto M. Treatment experience, frequency of dental visits, and children's dental fear: A cognitive approach. Eur J Oral Sci 2012;120:75-81.

4. Krikken JB, Veerkamp JS. Child rearing styles, dental anxiety and disruptive behaviour; An exploratory study. Eur Arch Paediatr Dent 2012;9 Suppl 1:23-8.

5. Klingberg G. Dental anxiety and behaviour management problems in paediatric dentistry - A review of background factors and diagnostics. Eur Arch Paediatr Dent 2012;9 Suppl 1:11-5.
6. American academy of pediatric dentistry reference manual 2011-2012. Pediatr Dent 2011;33:1-349.

7. Craske MG, Hermans D, Vansteenwegen D. Fear and learning: From basic processes to clinical implications. Michigan: American Psychological Association; 2006.

8. Pattwell SS, Lee FS, Casey BJ. Fear learning and memory across adolescent development: Hormones and behavior special issue: Puberty and adolescence. Horm Behav 2013;64:380-9.

9. Rachman SJ. Fear and Courage. New York: W. H. Freeman and Company; 1990.

10. Arnrup K, Berggren U, Broberg AG, Lundin SA, Hakeberg M. Attitudes to dental care among parents of uncooperative vs. Cooperative child dental patients. Eur J Oral Sci 2002;110:75-82.

11. Setiawan AS, Amriwijaya J, Fitriana E. Trans-adapted, reliability, and validity of children fear survey schedule-dental subscale in Bahasa Indonesia. Dent J 2015;48:1-6.

12. Yoshikawa H, Weisner TS, Kalil A, Way N. Mixing qualitative and quantitative research in developmental science: Uses and methodological choices. Qual Psychol 2013;1:3-18.

13. Patton MQ, Fund RE. Qualitative Research and Evaluation Methods. $3^{\text {rd }}$ ed. Thousand Oak: SAGE Publications; 2002. p. 1.

14. Macfarlane A, O'Reilly-de Brún M. Using a theory-driven conceptual framework in qualitative health research. Qual Health Res 2012;22:607-18

15. Du S, Jaaniste T, Champion D, Yap CS. Theories of fear acquisition: The development of needle phobia in children. Pediatr Pain 2008;10:13-8.

16. Muris P, Field AP. The role of verbal threat information in the development of childhood fear. "Beware the jabberwock!". Clin Child Fam Psychol Rev 2010;13:129-50.

17. Santrock J. Child Development: An Introduction. $14^{\text {th }}$ ed. New York; McGraw-Hill Education; 2014. p. 1. 